\title{
Special issue: honoring George A. Olah at 90
}

\author{
Istvan Hargittai ${ }^{1} \cdot$ Balazs Hargittai $^{2}$
}

Received: 13 December 2016 / Accepted: 13 December 2016 /Published online: 29 December 2016

(C) Springer Science+Business Media New York 2016

\begin{abstract}
This collection of contributions honors George A. Olah on the occasion of his 90th birthday.
\end{abstract}

\section{Keywords George A. Olah · G. K. Surya Prakash · Istvan} Orosz

We are pleased to present this special issue honoring the 90 -year old George A. Olah to the international community of structural chemists - in fact, all chemists. George Olah's activities and discoveries have embraced broad areas of chemistry and he utilized the most diverse techniques from syntheses to physical methods to computational studies. He has also worked with many associates from diverse areas both geographically and scientifically. A more extended paper about George A. Olah, his life and science, is the next Editorial in this issue [1]. We are gratified that the contributors of the papers in this

Istvan Hargittai

stuceditor@gmail.com

1 Department of Inorganic and Analytical Chemistry, Budapest University of Technology and Economics, P O Box 91, Budapest 1521, Hungary

2 Department of Chemistry, Saint Francis University, Loretto, PA 15940, USA collection represent laboratories in Canada, Germany, Hong Kong, Hungary, Ireland, Israel, Japan, Russia, Singapore, Spain, Sweden, and the USA.

It is our pleasure to acknowledge the kind assistance of G. K. Surya Prakash who helped us most efficiently in compiling the initial list of invitees for this special collection of papers. Dr. Prakash is Professor of Organic and Polymer Chemistry at the Department of Chemistry

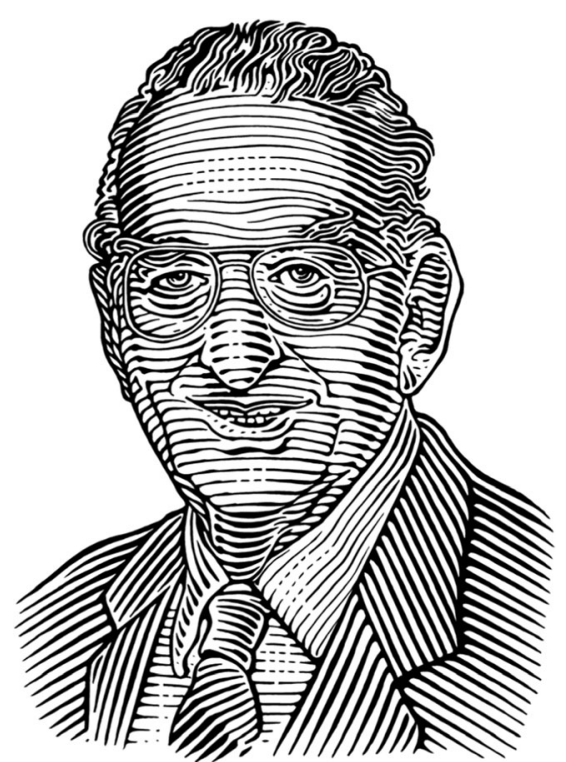

Fig. 1 Artist's rendition of George A. Olah's portrait—by Istvan Orosz 2016 
and the holder of the George A. and Judith A. Olah Nobel Laureate Chair in Hydrocarbon Chemistry at the Loker Hydrocarbon Research Institute, the University of Southern California.

We are also happy to thank our friend Istvan Orosz for his artistic rendering of George Olah's portrait (Fig. 1). Mr. Orosz is an internationally renowned Hungarian artist, graphic designer, printmaker, and animated film director. He has produced intriguing impossible objects, optical illusions and anamorphoses, often inspired by mathematical or scientific ideas.

\section{References}

1. Hargittai I (2017) Structures and mechanisms in chemical reactions: George A. Olah's life-long search of chemistry. Struct Chem. doi:10.1007/s11224-016-0814-x 